\title{
Microseismic monitoring and short term hazard assessments in underground coal mines
}

\author{
Stephen Meyer and Richard Lynch \\ Institute of Mine Seismology \\ Hobart, Australia \\ stephen.meyer@imseismology.org
}

\begin{abstract}
Large seismic events sometimes occur in underground coal mines - usually as the roof sandstone strata violently fail. Passive microseismic monitoring is a useful tool for monitoring the stability of these strata as mining progresses. The layered medium results in refracted seismic waves, and thus ray-tracing is used to more accurately locate seismic events once the $P$ - and $S$-wave arrivals have been identified on a number of associated seismograms. Source parameters such as radiated seismic energy and co-seismic inelastic deformation can be routinely quantified for each seismic event.
\end{abstract}

Often, microseismic event data exhibits precusory patterns before large-scale failures. These patterns range from simple increased seismic activity to simultaneous dropping of stress and accelerating deformation. Some examples from South African and Australian underground coal mines show that accelerating seismic activity correctly indicates large roof strata failures between 5 and 60 minutes in advance, in more than $75 \%$ of cases.

Keywords-microseismic monitoring; underground coal mines; seismic hazard

\section{INTRODUCTION}

Microseismic monitoring of mines is a technique routinely applied at over 300 mines around the world. It is the only technique capable of providing real-time $3 \mathrm{D}$ data on how the rock mass is responding to mining, and the field has matured considerably over the past 25 years e.g. [1].

Passive microseismic monitoring started in deep underground hard rock gold mines [2], but has also been applied in the hard rock open pit environment [3], [4], [5] and in the underground coal mine environment [6], [7], [8]. Underground coal mines are different to underground hard rock mines in many aspects, which have significant implications for the design and operation of microseismic monitoring systems, as well as the processing, analysis and interpretation of the recorded seismogram data.

\section{PAssive Microseismic Monitoring In COAL Mines}

While passive microseismic monitoring in underground hard rock mines is well established, adapting the technique to an underground coal mining environment requires some adjustments due to special features of coal mines. These can have implications on hardware considerations, array design and seismological aspects such as choice of velocity model. Perhaps the most characteristic aspect of coal mines is that they are generally very flat in layout and cover large horizontal spans. This mine layout generally means that the available locations to install seismic sensors from underground are also constrained to this planar configuration. Ideally, a planar configuration of seismic sensors is avoided as it can result in poor location accuracy. Location of seismic sources close to the plane experiences amplified errors in the direction perpendicular to the plane. "Fig. 1", compares a typical seismic array configuration in a hard rock underground mine with what could be expected in a coal mine. It shows that coal mines have a large horizontal span and very small vertical span. Hard rock underground mines tend to be the inverse, with a larger vertical spread of sensors and smaller horizontal spread, at least for steeply dipping ore bodies like in this example. For coal mines, sensors can generally be installed in vertical boreholes, in the roof or floor of access ways. Equipment availability and cost usually limits these boreholes to a depth of $50 \mathrm{~m}$ or less.

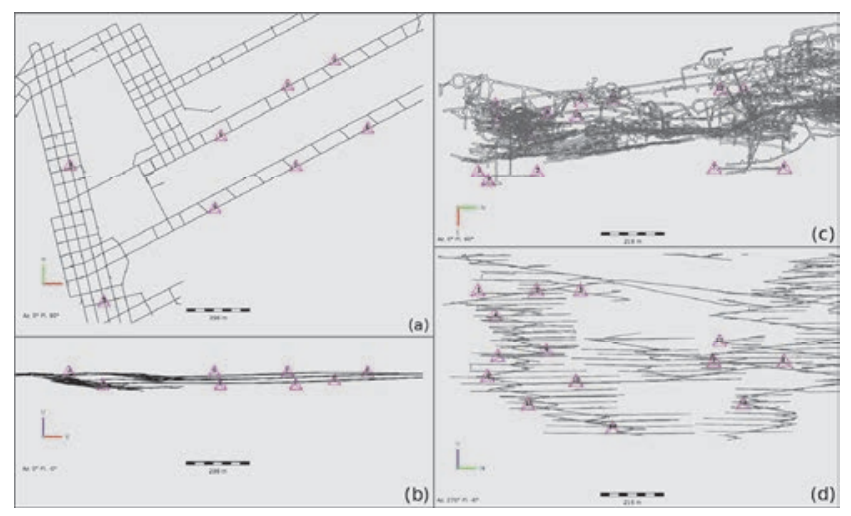

Fig. 1. Typical seismic array configuration for coal mine in plan (a) and section (b) views compared to a typical hard rock underground seismic array in plan (c) and section (d) views.

Another characteristic difference between coal and hard rock mines is that coal mining takes place at a faster rate than hard rock mining. In hard rock mines, an array of a few seismic sensors could be installed to monitor stopes that will be mined over the course of a few years while in coal mining a similar area can be mined out in a couple of months. Having portable seismic sensors would therefore be ideal, as 
they can be redeployed around areas of interest as active mining faces change. In hard rock underground mine, the sensors are installed and grouted in boreholes to provide good coupling to the rockmass and thus provide the best possible quality seismograms. This is obviously not ideal for coal mines. There are a few methods to install surface mounted portable seismic sensors:

- Attached to the side of the tunnel wall and covered in quick drying cement, known as a "swallow's nest" configuration

- Inside a surface mount sonde that is attached to the rockface with M10 bolts

- Attached to a standard roof bolt stub

"Fig 2 to 4" show examples of waveforms recorded at sensors installed in these methods.

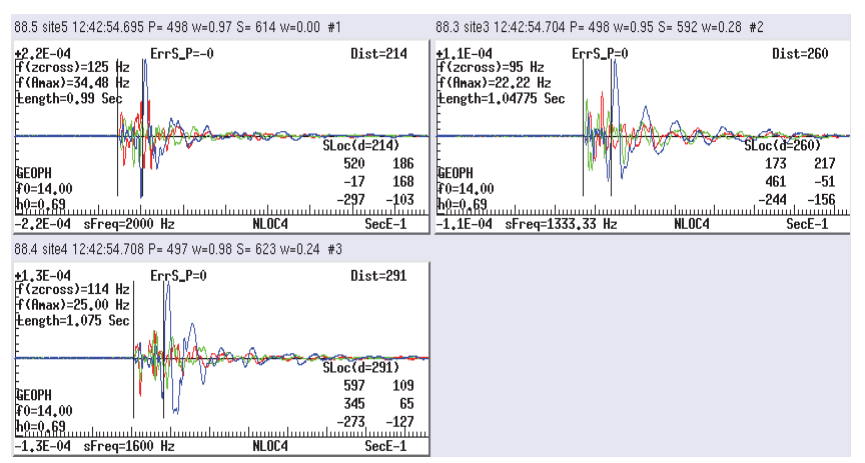

Fig. 2. Example of seismograms recorded at Brandspruit \#2 underground coal mine in South Africa. The geophones were affixed to the sidewall using quick-dry cement in a "swallow's nest" configuration. Chipping the cement away allows retrieval of the geophones after the measurements. The recorded waveforms are reasonably good quality, with even S-wave arrivals quite clear.

These all have the benefit are being portable and are easily installed on the sides and roofs of development excavations. However these do not always have good coupling to the solid rock mass and while they can be used for estimating the location of seismic events, they perform poorly for calculation of seismic source parameters. A solution to this is the recently developed removable borehole sensor. It is similar to a traditional borehole geophone, although instead of being grouted in the hole, a strong coupling to the rock mass is achieved through use of pneumatics that expand and push the sensor firmly against the borehole wall. This sensor provides the seismological benefits of being a borehole sensor and also the cost benefits of portable sensor. "Fig. 5", compares the waveforms recorded at one of these sensors alongside a traditional grouted borehole sensor adjacent to it. The waveforms have a common time and amplitude scale. Apart from some higher frequency noise on the removable sensor, the waveforms are identical. This would be of even less concern in a coal mining environment where seismic wave frequencies are lower than in hard rock.

Any hardware installed in a coal mine has to be certified to be intrinsically safe (IS) for operation in an environment with explosive gases. While IS versions of all hardware components can be produced, it is associated with additional complexity, increased cost and typically reduced specifications due to the need to keep power consumption below $110 \mathrm{~mW}$.

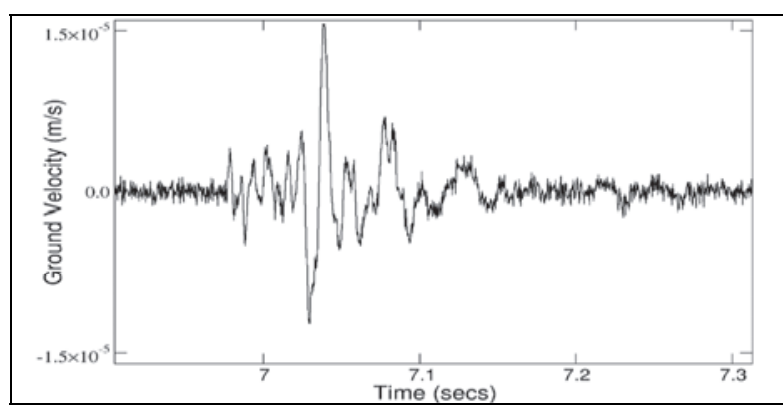

Fig. 3. Example of a seismogram recorded by a geophone inside a surface mounted sonde. The sondes can easily be removed and redeployed at another location. The waveforms is of quite high quality with clear P- and wave

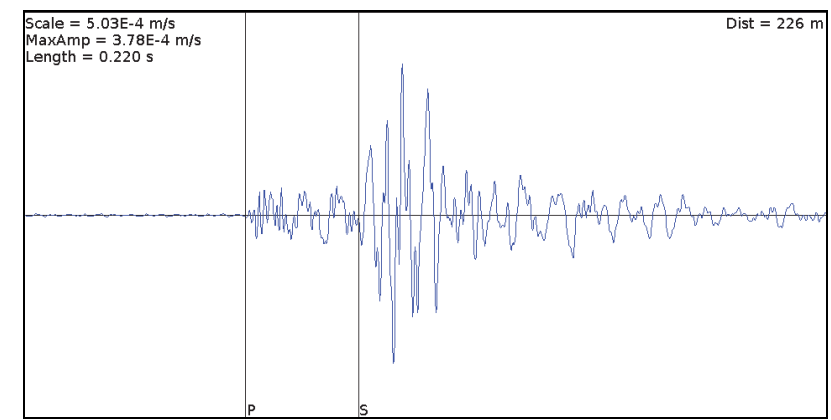

Fig. 4. Example of a seismogram recorded by a uni-axial $30 \mathrm{~Hz}$ geophone attached to a standard roof bolt stub at Brandspruit \#2 coal mine in South Africa. Despite this sub-optimal but removable method of connecting the geophone to the rock, the fairly clear seismogram displays distinct P- and S-wave arrivals.

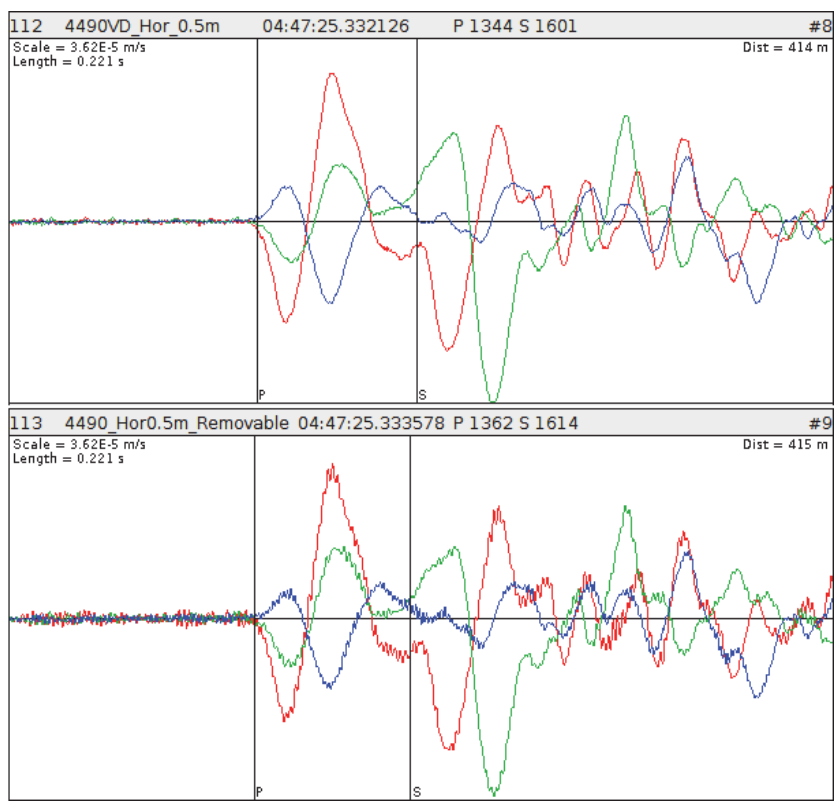

Fig. 5. Comparison of waveforms from the same event recorded by a geophone grouted in a borehole (top) and a removable geophone in a borehole next to the grouted one.

Microseismic monitoring in mines is generally performed either with geophones or accelerometers. For coal mines, 
geophones are generally recommended. They are more suited for lower frequency seismic waves which is what can be expected in coal mines due to the lower stress environment. Tri-axial geophones are best, as the capabilities of a tri-axial sensor allow for more advanced analysis and interpretation of seismic data. The underground array can be complimented with sensors installed on the surface of the Earth, directly above the mine. These can either be in boreholes from surface or as surface mounted sensors. The surface mounted sensors can be connected together to create a beam forming sensor that acts as a single sensor component but is comprised of many geophone element. These multiple components are normally arranged in a star shape and generally consist of 6 to 16 individual geophones. Combining the different components into a single sensor increases sensitivity to P-waves from below, while the spatial separation cancels out surface waves. Having at least a single sensor on the surface above the coal mine can be very useful for constraining the location of seismic events as well as more advanced analyses such as source mechanism inversion.

Locating seismic events requires an adequate and accurate implementation of the seismic velocity model around the mine. In hard rock underground mines, the velocity structure is often quite simple. The host rock mass tends to have a fairly uniform velocity distribution which is often assumed to be homogeneous with seismic waves travelling in straight rays for the purposes of routine seismic monitoring. These homogeneous velocities can easily be calculated by performing calibration blasts. Stopes and excavations can perturb this, although their effect is often not significant enough to cause major concern. The velocity structure in coal mines is very different. Coal seams exist in a layered medium, where different layers can have vastly different seismic velocities. Properly accounting for this layered media is required to accurately locate seismic events. This requires implementation of a 2D layered velocity model or full $3 \mathrm{D}$ velocity model. Calibration of seismic velocities in coal mines can also be challenging, as calibration blasts cannot be readily performed like in hard rock mines. Alternative solutions exist for this, such as percussion sources.

After an event has been located in terms of location, $\boldsymbol{X}=(x, y, z$,$) , and origin time, t$, the seismic source parameters need to be calculated to allow for any advanced analysis such as stability analysis. The two fundamental and independent source parameters are seismic potency, $P$, and radiated seismic energy $E$ [1]. Seismic potency is represents a volume of rock associated with co-seismic inelastic deformation at the source [9], [10]. For a generalised shape undergoing co-seismic inelastic deformation, the potency is the product of strain change and source volume

$$
P=\Delta V
$$

For a planar shear source, the potency is defined as $\mathrm{P}=\overline{\mathrm{u}}$.A where $\overline{\mathrm{u}}$ is the average slip and $\mathrm{A}$ is the source area. The potency is most commonly measured from the low frequency displacement plateau, $\Omega_{0}$, of the recorded waveforms [11].

$$
P_{P, S}=4 \pi v_{P, S} R \int_{0}^{t_{s}} u_{c o r r}(t) d t
$$

The energy release during fracturing and frictional sliding is due to the transformation of elastic strain into inelastic strain. The faster this fracturing, the higher the energy release. A quasi-static rupture would radiate practically no energy. The radiated energy of a seismic event is proportional to the integral of the radiation pattern corrected far-field velocity pulse squared $\dot{u}^{2}(t)$ of duration ts.

$$
E_{P, S}=\frac{8}{5} \pi \rho v_{P, S} R^{2} \int_{0}^{t_{S}} \dot{u}_{c o r r}^{2}(t) d t
$$

where $\rho$ is the rock density, $v_{\mathrm{P}, \mathrm{S}}$ is the $\mathrm{P}$ - or S-wave velocity and $\mathrm{R}$ is the distance from the source.

\section{PRECURSORY PATTERNS}

Deep underground hard rock mines, like the South African gold mines at depths of down to $4000 \mathrm{~m}$, have experienced large frequent damaging seismic events since the 1980 's. The ability to warn underground miners of impending large seismic events would be a boon to miner safety, and research has been conducted in this area in South Africa since 1996 [12]. Increases to microseismic activity was one of the first potential precursors to be investigated, but was found to be an unreliable indicator in the hard rock high stress environment. Instead derived parameters like Energy Index [13], Apparent Volume and Schmidt number [2] have been shown to provide some predictive success in the South African gold mines [14].

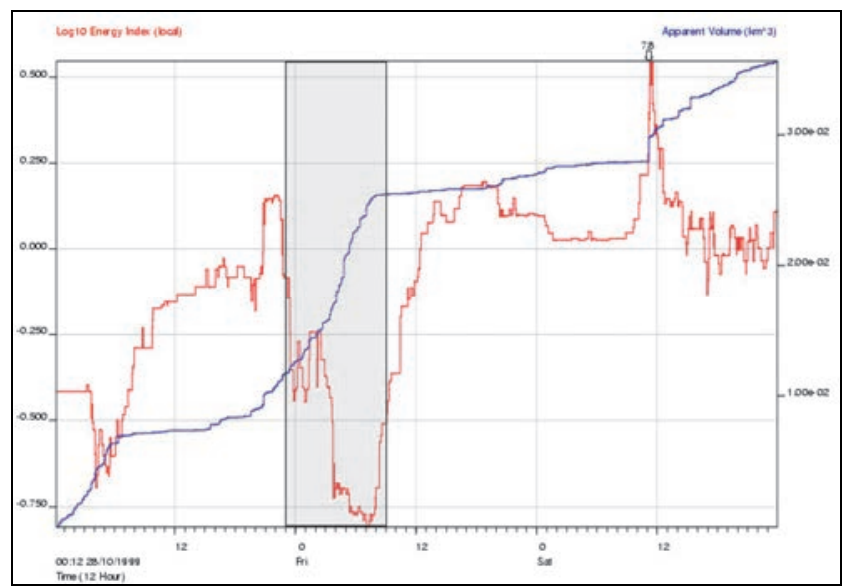

Fig. 6. The characteristic pattern of dropping energy index and accelerating cumulative apparent volume 30 hours prior to a large seismic event (local magnitude 2.4 in this case), from seismic data recorded at TauTona gold mine in South Africa. Data from the period of stress softening (shaded zone) can be used to spatially identify the zone of the future instability to within about $100 \mathrm{~m}$ - from [15]. 
Fig. 5 shows an example where these trends in cumulative apparent volume and Energy Index were observed before a large event in a South African gold mine. In underground coal mines, the greatest seismic hazard often results from violent failure of the roof strata. In this environment, the simple indicator of increasing microseismic activity is often correlated with large seismic events [16]. An early study shows that activity-based warnings at Moonee colliery in New South Wales, Australia resulted in false alarms $46 \%$ of the time [17]. However, $76 \%$ of significant roof falls and all of the major roof falls were successfully predicted in this way. Warning times were between a few seconds and 150 minutes, averaging about 50 minutes, which is quite practical in such a mining environment. In a more detailed analysis of this data, [18] calculated that the seismic data was able to give sufficient warning of impending roof falls about $90 \%$ of the time. "Fig. 6" contains an example of a successfully predicted roof fall at Moonee colliery using microseismic data.

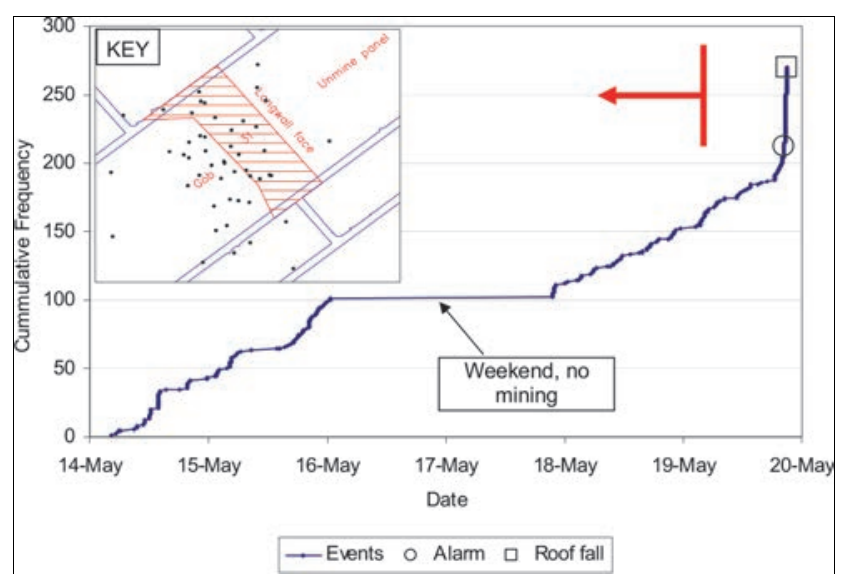

Fig. 7. Cumulative frequency of seismic events associated with the impending roof fall. The location of events, occurring within the forecast window between the seismic alarm and the roof fall, is also shown (inset). From [19].

\section{CONCLUSIONS}

Microseismic monitoring has long been established as a standard technique for underground hard rock mines. It has been demonstrated at a number of coal mines, but is still not routinely used in most countries. Many of the methods that have become common practise in hard rock underground mines can be transferred to coal, although some adaptations are required. The planar configuration of arrays can be a challenge and needs to be taken into consideration from the early stages of planning the monitoring system. This is especially true due to long boreholes with permanent geophones not being practical for the rapid mining seen in coal mines.

Work at Australian and South African coal mines has demonstrated that seismic activity can be reliably used to indicate impending failure of the roof strata. Developments in hardware are making the use of microseismic monitoring systems in coal mines more attractive. We expect that these developments and the 25 years experience in hard rock mine seismic monitoring will lead to these techniques becoming more popular and common in coal mines in the near future.

\section{REFERENCES}

[1] A.J. Mendecki, "Seismic Monitoring in Mines," London: Chapman and Hall, 1997.

[2] A.J. Mendecki, "Real time quantitative seismology in mines," Proc. 3rd Int. Sym. on Rockbursts and Seismicity in Mines, Queen's Uni., Canada. 1993.

[3] R.A. Lynch, R. Wuite, B.S. Smith, and A. Cichowic, "Micro-Seismic Monitoring of Open Pit Slopes," Proc. $6^{\text {th }}$ Int. Sym on Rockbursts and Seismicity in Mines, pp. 581-592, 2005.

[4] R.A. Lynch, and D.A. Malovichko, "Seismology and slope stability in open pit mines," International Symposium on Stability of Rock Slopes, pp. 375-390, 2006.

[5] S.G. Meyer, "Slope deformation mechanics from microseismic monitoring," Proc. SAIMM Slope Stability Conference, Cape Town, South Africa, Oct 12-14, 2014.

[6] S.M. Toon, and P. Styles, "Microseismic event location around longwall coal faces using borehole in-seam seismology," Proc. 3rd Int. Sym. on Rockbursts and Seismicity in Mines, Queen's Uni., Canada.1993.

[7] Hatherley and X. Luo, "Seismic monitoring of ground caving processes associated with longwall mining of coal." Proc. 4th Int. Sym. on Rockbursts and Seismicity in Mines, Krakow, Poland, 1997.

[8] D. Minney, D. Kotze, and G.V. Aswegen, Seismic monitoring of the caving process above a retreating longwall at New Denmak Colliery, South Africa," Proc. 4th Int. Sym. on Rockbursts and Seismicity in Mines, Krakow, Poland, 1997.

[9] A. Ben-Menahem, and S.J. Singh, "Seismic Waves and Sources. Springer-Verlag, New York, 1981.

[10] C.G.P. King, G. "Geological faults, fractures, creep and strain. Philosophical Transactions of the Royal Society of London. Series A. Mathematical and Physics Sciences, 288(1350), pp. 197-212, 1978.

[11] V.I. Keilis-Borok, "On estimation of the displacement in an earthquake source and of source dimensions. Annali di Geofisica, 12(2), pp. 205-214, 1959.

[12] MHSC, http://www.dmr.gov.za/mine-health-a-safety/occupationalsafety.html, 2016.

[13] G.V. Aswegen, and A.G. Butler, "Applications of quantative seismology in South African gold mines," Proc. 3rd Int. Sym. on Rockbursts and Seismicity in Mines, Queen's Uni., Canada, 1993.

[14] V. Aswegen and Mendecki, "Mine layout, geological features and seismic hazard," GAP303 research project - final report, SIMRAC, South Africa, 1999.

[15] R.A. Lynch, and A.J. Mendecki, "High-resolution seismic monitoring in mines," Proc. 5th Int. Sym. on Rockbursts and Seismicity in Mines, Johannesburg, South Africa, 2001.

[16] W.D. Beer, "Investigation into the possibility of predicting goafing by micros seismic monitoring techniques," SIMRAC technical report, 2000.

[17] J. Edwards, "Seismic monitoring for windblast prediction," Mine Seismicity and Rockburst Rick Managerment in Underground Mines, ACG, 1998.

[18] P. Hayes, "Moonee Colliery: Renewing the Economic Viability of a Mine Using Microseismic and Hydraulic Fracturing Techniques in Massive Roof Conditions," In Proceedings, 19th International Conference on Ground Control in Mining, Morgantown, WV, Aug. 810, pp. 38-44, 2000.

[19] A.T. Iannacchione, T.S. Bajpayee and J.L. Edwards, "Forecasting Roof Falls with Monitoring Technologies - A look at the Moonee Colliery Experience," In Proceedings, 24th International Conference on Ground Control in Mining, Morgantown, WV, Aug. 2-4, pp. 44 51,2005 . 